\title{
Implementasi Konsep Gamification pada Aplikasi Terapi Autis dengan Metode Applied Behavior Analysis
}

\author{
Donni Prabowo*1, Ema Utami ${ }^{2}$, Hanif Al Fatta ${ }^{3}$ \\ ${ }^{1,2,3}$ Magister Teknik Informatika STMIK AMIKOM Yogyakarta

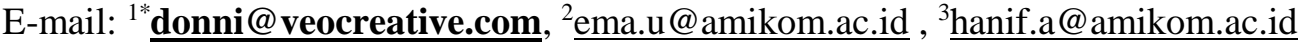

\begin{abstract}
Abstrak
Autisme merupakan gangguan yang dialami sejak lahir ataupun saat balita. Gangguan ini merupakan kelainan perkembangan sistem saraf pada seseorang. Penderita autisme umumnya mengalami kesulitan dengan fungsi sosial, motorik, sensorik, dan kognitif. Salah satu penanganan autisme yaitu dengan melakukan terapi. Metode terapi autis yang paling sering digunakan sampai saat ini yaitu metode Applied Behavior Analisyst (ABA). Saat ini penerapan konsep permainan atau gamification merupakan salah satu cara untuk membuat penderita autism antusias untuk melakukan terapi, oleh karena itu penelitian ini akan membahas perancangan aplikasi game terapi autis pada empat bidang yang menjadi masalah bagi penderita autism yaitu bidang sosial, motorik, sensorik, dan kognitif. Rancangan aplikasi game terapi ini akan diterapkan pada sistem terapi autis yang menerapkan metode ABA yaitu sistem Ahada (ahada.info). Pendekatan yang digunakan dalam proses perancangan game terapi pada penelitian ini adalah model Game Design Document menurut Adams Ernest. Penelitian ini menghasilkan kesimpulan yang menyatakan bahwa implementasi konsep game pada sistem terapi autis Ahada dapat diterapkan dengan menggunakan pendekatan Game Design Document. Pendekatan ini dinyatakan sebagai pendekatan yang baik untuk digunakan dalam proses perancangan game. Selain itu, penelitian ini juga menyatakan bahwa penerapan konsep Natural User Interface (NUI) dapat diintegrasikan dengan sistem Ahada untuk memenuhi kebutuhan terapi motorik.
\end{abstract}

Kata Kunci - Gamification, Aplikasi Terapi Autis, ABA, Ahada

\begin{abstract}
Autism is disorder experienced since the time of birth or infancy. This disorder is developmental disorder of the nervous system in person. People with autism generally have difficulty with social, motor, sensory, and cognitive. One of autism treatment is therapy. Autism treatment methods are most commonly used to date are Applied Behavior Analisyst method $(A B A)$. Now, game concept application is one way to create enthusiasm for autism therapy, therefore this research will discuss about design of autism therapy game on four areas that become problem for people with autism are social, motor, sensory, and cognitive. The design of the therapy game application will be applied to autism therapy system that implements the method ABA, that is Ahada system. The approach used in the game design process of therapy in this study is Game Design Document by Ernest Adams. This study resulted conclusion that the concept of gaming on Ahada autism therapy system can be implemented by using Game Design Document. This approach is expressed as good approach to use in game design process. In addition, this study also stated that the application of the Natural User Interface concept can be integrated with the system to meet the needs motor therapy.
\end{abstract}

Keywords - Gamification, Autism Therapy Application, ABA, Ahada 


\section{PENDAHULUAN}

Autisme pertama kali ditemukan oleh Leo Kanner pada tahun 1943. Kanner mendeskripsikan gangguan ini sebagai ketidakmampuan untuk berinteraksi dengan orang lain, gangguan berbahasa yang ditunjukkan dengan penguasaan bahasa yang tertunda, echolalia, mutism, pembalikan kalimat, adanya aktivitas bermain repetitive dan stereotype, rute ingatan yang kuat dan keinginan obsesif untuk mempertahankan keteraturan didalam lingkungannya.[1]

Ryan mengatakan bahwa metode Applied Behavior Analysis (ABA) merupakan metode yang paling efektif digunakan dalam terapi Autis. Dalam penelitian ini dijelaskan mengenai cara-cara atau langkah-langkah yang harus dilakukan untuk menerapkan metode ABA. Metode ABA sendiri adalah pendekatan ilmiah untuk mengevaluasi perilaku. Metode ini menyediakan informasi ilmiah yang dapat membantu dan memandu pendekatan-pendekatan terapi perilaku yang dapat merujuk pada setiap terapi perilaku yang memanfaatkan berbagai informasi ilmiah tentang perilaku. Tujuan dasar $A B A$ adalah membentuk perilaku yang lebih dapat diterima lingkungan sosial dan mengurangi perilaku yang bermasalah. Metode ABA merupakan suatu metode yang banyak digunakan dalam pembelajaran dan terapi bagi anak autis untuk memberikan rangsangan perkembangan sensorik, motorik, sikap dan perilaku sehingga komunikasi, interaksi sosial, sikap, perilaku dan emosional dapat berkembang.[2]

Metode ABA didasarkan pada teori Operant Conditioning yang dikembangkan oleh Skinner. Teori Operant Conditioning merupakan bentuk pembelajaran dimana sebuah respon meningkat frekuensinya karena disebabkan oleh penguatan positif maupun negatif. Yang dimaksud penguat positif dan negatif pada kasus ini merupakan dorongan atau motivasi terkait dengan perilaku yang harus dilakukan atau harus tidak dilakukan.[3]

Helmi Adly pada penelitiannya mengemukakan bahwa serious game merupakan salah satu cara yang relevan untuk mengatasi beberapa masalah manusia seperti autisme. Serious game merupakan suatu konsep game dengan tujuan untuk kepentingan trainning, advertising, simulasi, edukasi. Intinya adalah untuk kepentingan yang sifatnya non-entertainment. Implementasinya, konsep game atau gamification ini bisa diterapkan untuk berbagai tingkatan usia serta dengan berbagai genre dan teknologi game. Dalam penelitiannya, dijelaskan bahwa permainan atau game sangat efektif untuk disisipkan dalam kegiatan terapi dan pendidikan autism anak.[4]

Teknologi augmented reality merupakan salah satu solusi terapi alternatif bagi penderita gangguan autisme. Dalam penelitian Casas ini juga membahas pemanfaatan Microsoft Kinect sebagai Motion Sensor Augmented Reality. Microsoft Kinect adalah perangkat yang menggunakan gerakan penggunanya sebagai controler. Microsoft Kinect dibangun oleh Rare, Rare merupakan anak perusahaan dari Microsoft Game Studios. Pada penenelitian ini dibahas mengenai teknis penerapan Microsoft kinect pada Augmented Reality dengan metode research and development.[5]

Apabila dicermati secara lebih mendalam, metode terapi autis ABA memiliki kesamaan dengan konsep gamification, yaitu memberi penghargaan atau apresiasi kepada user apabila berhasil melakukan sesuatu yang ditargetkan dan memotivasi user untuk mencoba kembali apabila belum bisa mencapai target yang diinginkan. Oleh karena itu pada penelitian ini penulis mencoba untuk menerapkan konsep game pada sistem terapi autis yang menerapkan metode ABA. Dalam perancangan aplikasi game ini juga dibahas penerapan konsep Natural User Interface (NUI) menggunakan Microsoft Kinect dan Device Touch Screen untuk kebutuhan terapi motorik. 
Ahada merupakan salah satu sistem terapi dan sitem informasi yang menerapkan metode terapi ABA. Ahada merupakan sebuah sistem informasi yang didalamnya terdapat framework aplikasi terapi autis yang terbagi menjadi 4 kategori utama, yaitu kategori terapi motorik, terapi sensorik, terapi sosial, dan terapi kognitif. Saat ini jumlah aplikasi terapi pada Ahada masih sangat terbatas dan butuh dikembangkan, oleh karena itu penulis akan membuat rancangan aplikasi terapi autis dengan menerapkan konsep game pada aplikasi terapi autis tersebut.

Menurut Adams Ernest, Game Design Document merupakan kumpulan dokumendokumen yang digunakan game designer untuk menginformasikan mengenai game yang didesain, proses ini mengubah ide yang tadinya abstrak menjadi rencana tertulis. Game Design Document dapat dibagi menjadi 7 game dokumen antara lain: High Concept Document, Game Treatment Document, Character Design Document, World Design Document, Flowboard, Story And Level Progression Document, dan The Game Script. Dikarenakan perancangan pada penelitian ini merupakan perancangan game, maka pendekatan yang akan digunakan yaitu pendekatan dengan model Game Design Document.[6]

\section{METODE PENELITIAN}

Metode penelitian yang digunakan dalam penelitian ini adalah metode Reverse Engineering Research. Metode ini merupakan turunan dari metode penelitian Research and Development $(R \& D)$. Reverse Engineering Research yaitu upaya abstraksi dari produk, sistem, atau prototype yang sudah ada menjadi blue print, formula, atau model. Penelitian dimulai dari abstraksi yang lebih rendah menuju ke setingkat atau beberapa tingkat lebih tinggi untuk megeksplorasi suatu sistem atau produk yang sudah ada (explanatory research). Suatu sistem perlu di reverse kembali ketika sistem tidak dapat meminimalkan biaya, tidak mampu mengakomodasi perubahan fungsional atau sistem masih perlu dikembangkan lebih dalam lagi untuk memunuhi kebutuhan-kebutuhan fungsional yang masih belum terakomodir.[7] Dalam hal ini sistem Ahada merupakan sebuah sistem yang perlu reverse atau dikembangkan lagi karena pada bagian terapi yang ada pada sistem ahada masih berpeluang untuk dikembangkan lagi. 
Citec Journal, Vol. 1, No. 3, Mei 2014 - Juli 2014
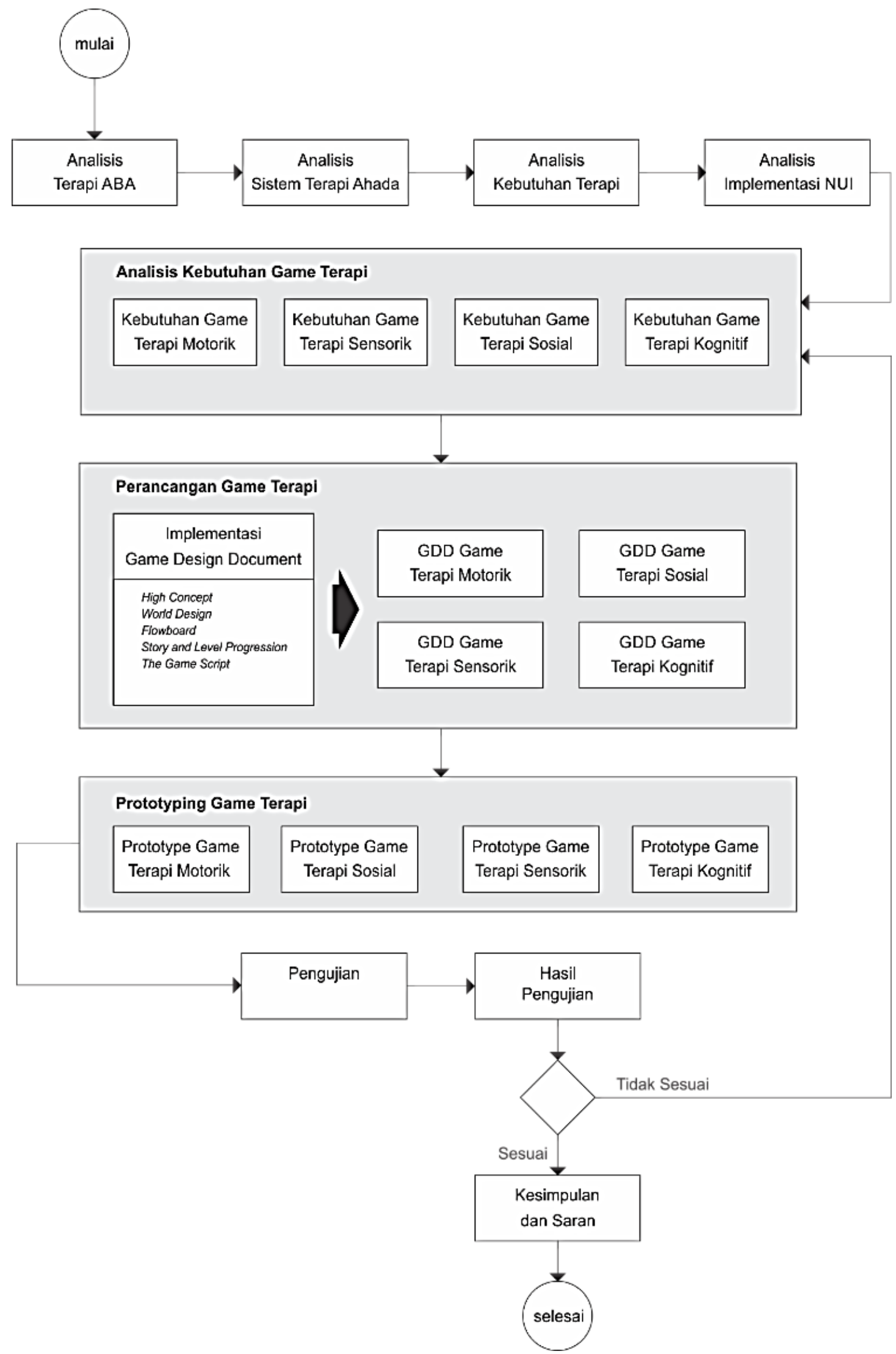

Gambar 1. Bagan Alur Penelitian 
Gambar 1 merupakan bagan alur penelitian yang akan dilakukan oleh penulis. Sesuai yang telah dijabarkan pada gambar tersebut, penelitian ini dimulai dengan menganalisis metode ABA, dilanjutkan dengan analisis arsitektur sistem ahada secara umum, dilanjutkan analisis kebutuhan terapi sampai yang terakhir adalah melakukan pengujian aplikasi game terapi dengan kebutuhan fungsional game terapi.

\section{HASIL DAN PEMBAHASAN}

\subsection{Analisis Metode ABA}

Metode ABA merupakan salah satu metode terapi autis yang kompleks, namun metode ini yang paling sering digunakan untuk terapi autis, oleh karena itu rancangan aplikasi terapi yang penulis rancangan harus disesuaikan dengan metode tersebut. Tabel 1 merupakan rumusan kriteria penerapan metode ABA pada aplikasi terapi Autis yang penulis rancang.

Tabel 1. Rencana Implementasi Metode ABA

\begin{tabular}{|l|l|}
\hline \multicolumn{1}{|c|}{ Kriteria ABA (Handojo) } & \multicolumn{1}{|c|}{ Rencana Implementasi } \\
\hline $\begin{array}{l}\text { Materi harus dimulai dengan kepatuhan dan } \\
\text { kontak mata. Keduanya harus dikuasai anak } \\
\text { dengan baik. Semakin konsisten, semakin baik. }\end{array}$ & $\begin{array}{l}\text { Salah satu cara untuk membuat siswa dapat } \\
\text { berlatih untuk lebih fokus yaitu dengan } \\
\text { menggunakan konsep live view, sehingga } \\
\text { siswa dapat melihat dirinya sendiri seperti } \\
\text { bercermin. Namun dalam hal ini aplikasi } \\
\text { terapi yang penulis rancang hanya berperan } \\
\text { sebagai alat bantu bagi seorang terapis untuk } \\
\text { melatih siswa agar bisa fokus terhadap } \\
\text { aplikasi, jadi penggunaanya akan tetap } \\
\text { membutuhkan seorang terapis. }\end{array}$ \\
\hline $\begin{array}{l}\text { Kemudian, ajarkan kemampuan menirukan dan } \\
\text { berlanjut ke kemampuan bahasa reseptif atau } \\
\text { kognitif. Lanjutkan terus ke kemampuan } \\
\text { bahasa ekspresif. Perlu diketahui bahwa } \\
\text { kadang-kadang dijumpai anak autis yang lebih } \\
\text { mudah memahami bahasa reseptif daripada } \\
\text { menirukan. }\end{array}$ & $\begin{array}{l}\text { Dari observasi yang penulis lakukan ternyata } \\
\text { penderita autis memang lebih mudah } \\
\text { memahami interuksi dengan cara menirukan. } \\
\text { Oleh karena itu sebelum terapi dimulai } \\
\text { penderita akan diminta menirukan beberapa } \\
\text { interuksi, misalnya mengangkat tangan. }\end{array}$ \\
\hline $\begin{array}{l}\text { Kemampuan akademik baru diajarkan apabila } \\
\text { kemampuan bahasa reseptif telah dikuasai } \\
\text { anak. }\end{array}$ & $\begin{array}{l}\text { Pada aplikasi ini akan ada 4 kategori terapi } \\
\text { autis, Jadi setelah penderita mampu } \\
\text { memahami dan menyesuaikan diri terhadap } \\
\text { aplikasi, seorang terapis dapat masuk pada } \\
\text { kategori terapi sesuai yang dibutuhkan. }\end{array}$ \\
\hline $\begin{array}{l}\text { Pada awal terapi mulailah dengan jumlah } \\
\text { aktivitas yang kecil. Bila ternyata kemampuan } \\
\text { anak tinggi, jumlah aktivitas yang diajarkan } \\
\text { boleh disesuaikan }\end{array}$ & $\begin{array}{l}\text { Seorang terapis dapat memilih sendiri terapi } \\
\text { apa yang dibutuhkan penderita sesuai dengan } \\
\text { tingkat kemampuan penderita berdasarkan } \\
\text { kategori terapi dan game terapi yang tersedia. }\end{array}$ \\
\hline $\begin{array}{l}\text { Urutan aktivitas yang diajarkan sebaiknya } \\
\text { konsisten agar lebih mudah dikuasai anak. }\end{array}$ & $\begin{array}{l}\text { Aplikasi akan mencatat seluruh } \\
\text { perkembangan penderita melalui aplikasi } \\
\text { terapi ini, sehingga terapis dapat memantau } \\
\text { konsistensi perkembangan siswa. }\end{array}$ \\
\hline
\end{tabular}




\subsection{Analisis Kebutuhan Terapi Autis}

\subsubsection{Analisis Kebutuhan Terapi}

1. Kebutuhan Terapi Motorik

Terdapat beberapa kebutuhan yang harus dipenuhi pada terapi motorik antara lain sebagai berikut

a. Terapi ini ditekankan untuk melibatkan fungsi motorik kasar penderita seperti mengayunkan tangan, bergerak ke kanan atau ke kiri, dan memukul.

b. Terapi ini ditekankan untuk dapat melibatkan fungsi motorik halus penderita seperti menyentuh dan menekan sesuatu.

c. Terapi dilakukan secara konsinten dan dicatat untuk mengetahui progress perkembangan motorik penderita.

2. Kebutuhan Terapi Sensorik

Terdapat beberapa kebutuhan yang harus dipenuhi pada terapi sensorik bagi penderita ganguan autisme antara lain

a. Terapi ini harus ditekankan pada fungsi sensorik penderita, fungsi sensorik yaitu fungsi yang berkaitan dengan panca indra, yaitu penglihatan, pendengaran, penciuman, perasa, peraba. Terapi pendengaran bisa berupa terapi musik atau terapi mengenal macammacam suara, sedangkan untuk peraba biasanya dengan terapi pijat memijat.

b. Terapi harus selalu di catat dan dilakukan secara konsinten untuk mengetahui progress perkembangan sensorik penderita.

3. Kebutuhan Terapi Sosial

Beberapa kebutuhan yang harus dipenuhi pada terapi sosial pada penderita ganguan autisme antara lain

a. Terapi harus ditekankan untuk melatih interaksi sosial penderita, misalnya mengajarkan cara menyapa, mengankat telepon, atau cara bertamu.

b. Terapi harus merangsang penderita untuk mau berinteraksi khususnya bicara.

c. Perkembangan terapi harus di catat dan dilakukan secara konsinten untuk mengetahui progress perkembangan sosial penderita.

4. Kebutuhan Terapi Kognitif

Pada kategori terapi ini terdapat beberapa kebutuhan yang harus dipenuhi pada kategori terapi kognitif antara lain

a. Terapi ini harus dapat melatih kecerdasan penderita, misalnya kemampuan membedakan warna atau kemampuan mencocokkan benda sejenis, kemampuan menghitung, dan lain sebagainya.

b. Terapi harus selau di catat dan dilakukan secara konsinten untuk mengetahui progress perkembangan sosial penderita. 


\subsection{Analisis Sistem Terapi Ahada}

Sistem yang dimaksud dalam point ini adalah sistem Ahada secara keseluruhan. Gambar 2 adalah bagan yang dapat menjelaskan sistem Ahada.

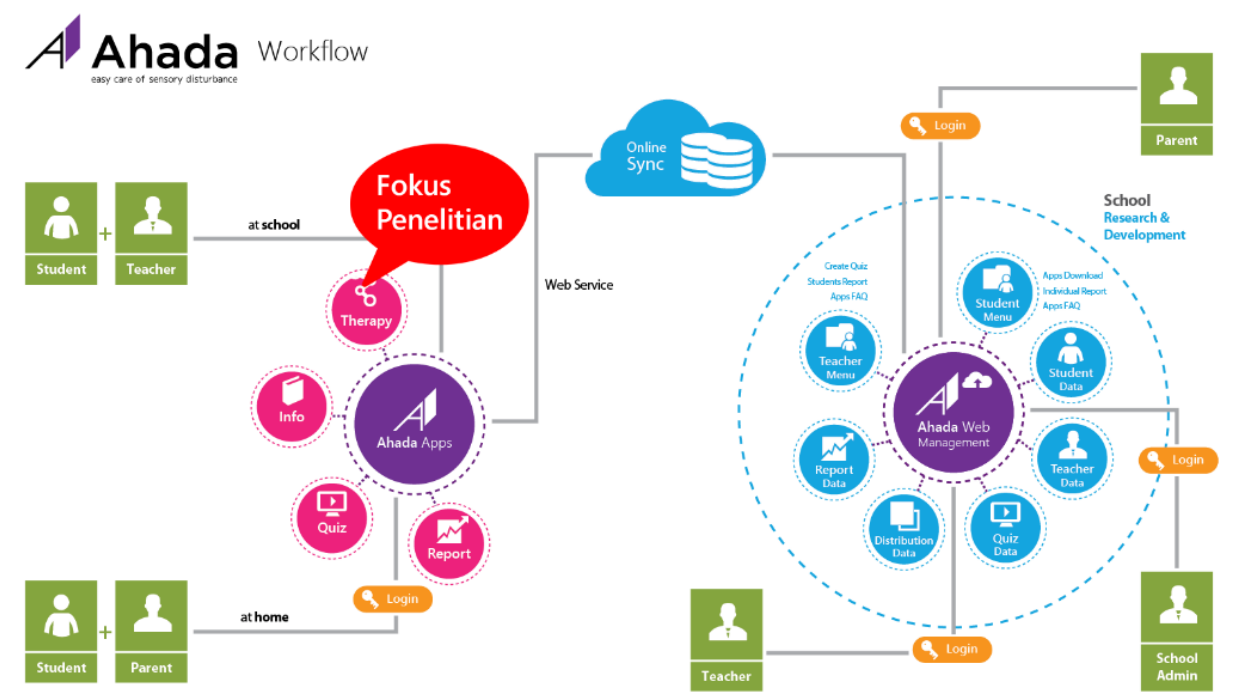

Gambar 2. Ahada Workflow

Pada sisi sebelah kiri adalah aplikasi desktop Ahada yang dapat digunakan oleh siswa didampingi orang tua ketika di rumah atau gurunya ketika di sekolah. Data-data dari terapi yang telah dilakukan oleh siswa akan disimpan dan dikirim ke aplikasi konten manajemen yang ada pada sisi sebelah kanan. Pada sisi manajemen, semua data yang diperoleh dapat dimanfaatkan untuk keperluan riset dan pengembangan metode pembelajaran untuk anak autis. Data ini juga digunakan sebagai media pelaporan hasil perkembangan siswa yang menggunakan aplikasi ini.

Pada penelitan ini, penulis hanya memfokuskan atau menekankan pada rancangan aplikasi terapi autis saja. Penulis akan merancang empat macam aplikasi terapi autis berbasis game yang terbagi pada empat kategori berbeda yaitu kategori motorik, sensorik, sodial, kognitif. Rencana penerapan metode ABA yang dijelaskan pada tabel 1 akan dijadikan dasar untuk merumuskan kebutuhan game terapi pada masing-masing kategori terapi pada sistem ahada.Gambar 3 menjelaskan tentang ilustrasi aplikasi terapi yang akan diterapkan pada sistem Ahada.

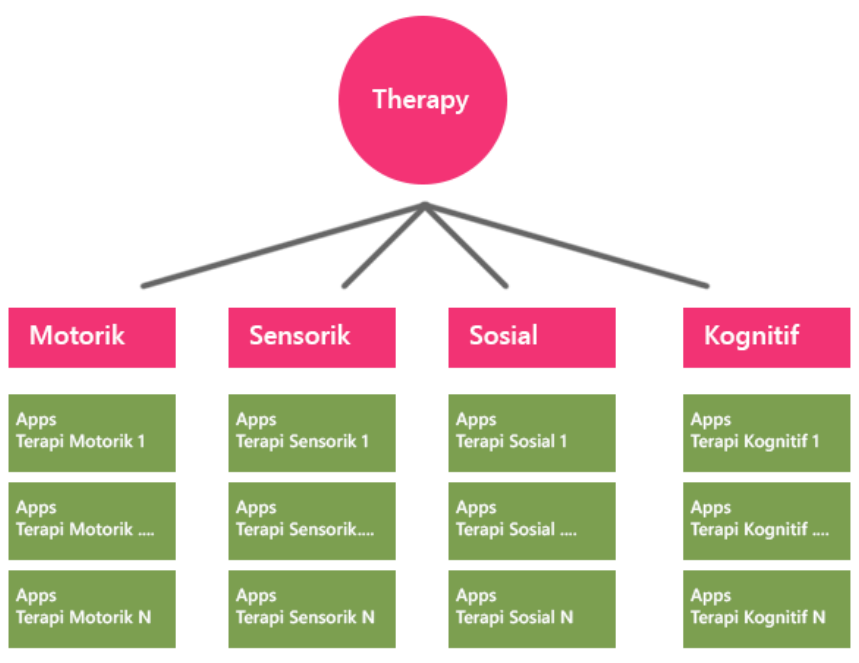

Gambar 3. Bagan Aplikasi Terapi Autis pada Sistem Ahada 


\subsection{Analisis Natural User Interface (NUI)}

NUI adalah suatu bentuk antarmuka yang memungkinkan pengguna mengoperasikan aplikasi sebagaimana mereka berinteraksi sehari-hari. Interaksi yang dimaksud seperti, membalik halaman buku saat membaca, menulis dengan tangan untuk mencatat, serta penggunaan gesture lainnya.

Dalam hal ini untuk melatih fungsi motorik penderita tentunya harus menggunakan konsep NUI, oleh karena itu dibutuhkan sebuah hardware yang mampu mengakomodir konsep tersebut. Pada penelitian ini penulis akan menggunakan device touch screen windows 8 untuk terapi motorik halus seperti menyentuh, menekan, memegang, sedangkan untuk terapi motorik kasar memukul, meloncat atau berjalan penulis akan menggunakan hardware Micosoft Kinect untuk mendeteksi rangka tubuh user dan mengolahnya menjadi sumber inputan yang dapat dimanfaatkan untuk kebutuhan terapi motorik.
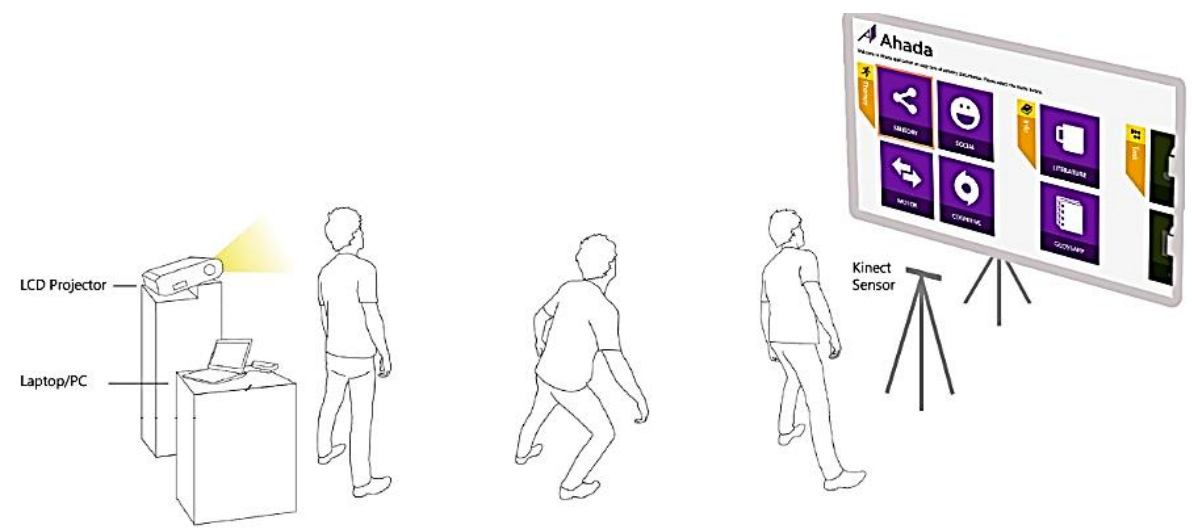

Gambar 4. Ilustrasi Interaksi User terhadap Aplikasi

Gambar 4 merupakan ilustrasi penerapan hardware kinect untuk menghasilkan interaksi yang natural antara user dengan aplikasi game terapi, sedangkan gambar 5 merupakan skema alur kerja Microsoft Kinect hingga dapat dijadikan salah satu sumber input pada sistem Ahada.

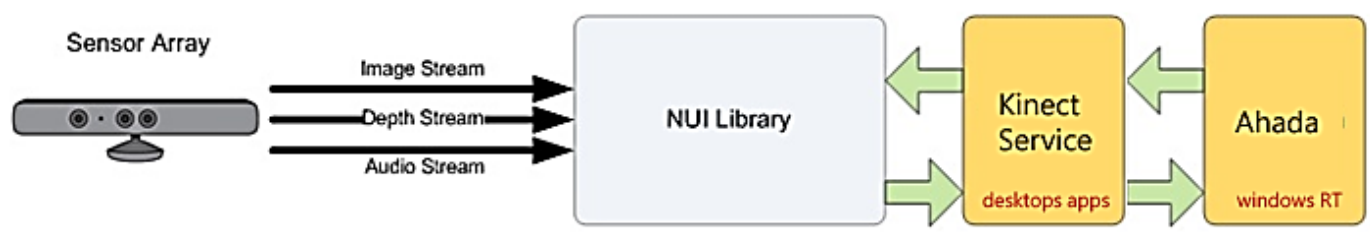

Gambar 5. Skema alur kerja kinect pada sistem Ahada

Aplikasi Ahada merupakan aplikasi yang berjalan pada windows runtime, sedangkan SDK Kinect hanya dapat berjalan pada windows klasik (x86/x64), oleh karena itu dibutuhkan penghubung agar kinect dapat di akses di windows runtime. Kinect service salah satu solusi untuk mengatasi masalah tersebut. Service yang publikasikan di website http://brianpeek.com/ ini dapat menggubungkan keduanya sehingga dapat saling berkomunikasi.

\subsection{Perancangan Game Terapi}

Perancangan game terapi pada penelitian ini melibatkan lima dari tujuh model game document menurut Adams Ernest, yaitu High Concept Document, World Design Document, Flowboard, Story and Level Progression Document, dan The Game Script. 


\subsubsection{Aplikasi Game Motorik}

Game terapi autis yang penulis rancang ini berjudul "Fun Bubble Pop". Konsep dari Fun Bubble Pop cukup sederhana yaitu user diminta untuk meletuskan gelembung dengan tangan kanan atau kanan kiri penderita sesuai dengan intruksi yang muncul. Tujuan dari game ini adalah merangsang fungsi motorik penderita dengan cara menggerakkan tangan sampai menyentuh gelembung, dengan menerapkan konsep Augmented Reality penderita akan melihat dirinya sendiri pada layar monitor seperti bercermin, kemudian akan muncul gelembunggelembung yang melayang-layang penderita, gelembung itulah yang harus dipecahkan secepat mungkin.

\subsubsection{Aplikasi Game Sensorik}

Game terapi autis yang penulis rancang ini berjudul "Sound of the World". Konsep dari Sound of the World yaitu aplikasi akan mengeluarkan suatu suara, dan user harus mengidentifikasi suara apakah yang dikeluarkan aplikasi, selanjutnya tinggal memilih gambar yang relevan dengan suara tersebut. Tujuan dari game ini adalah merangsang fungsi sensor pendengaran penderita, serta kemampuan kognitif mengidentifikasi suara.

\subsubsection{Aplikasi Game Sosial}

Game terapi autis ini berjudul "Activity Sort". Konsep dari Activity Sort yaitu aplikasi akan menampilkan screenshot dan keterangan mengenai aktifitas tertentu secara acak. User diminta untuk mencoba mengurutkan aktifitas tersebut dengan benar. Setelah user berhasil mengurutkan aktifitas dengan sempurna maka akan muncul video utuh yang menggambarkan tentang aktifitas tersebut secara benar.

\subsubsection{Aplikasi Game Kognitif}

Game terapi autis yang penulis rancang ini berjudul "Pick and Match". Konsep dari Pick and Match cukup sederhada yaitu user diminta untuk menjodohkan benda yang berasosiasi sesuai dengan interuksi yang diberikan oleh aplikasi. Penderita gangguan autis dapat melakukan terapi ini dengan media touch screen.

\subsection{Pengujian}

Metode pengujian yang digunakan pada penelitian ini adalah metode pengujian Black Box. Pengujian Black Box adalah pengujian aspek fundamental sistem tanpa memperhatikan struktur logika internal perangkat lunak. Pengujian ini digunakan untuk memastikan perangkat lunak berfungsi dengan benar. Pada penelitan ini pengujian dilakukan dengan cara mensimulasikan aplikasi ini pada kegiatan terapi anak autis dan melakukan pengamatan atas hasil yang dicapai terhadap kebutuhan fungsional game terapi. Berikut ini merupakan pengujian black box atas prototype aplikasi game terapi yang penulis rancang.

\subsubsection{Pengujian Game Terapi Motorik - Fun Bubble Pop}

Tabel 2. Pengujian Game Terapi Motorik - Fun Bubble Pop

\begin{tabular}{|l|l|l|}
\hline \multicolumn{1}{|c|}{ Kasus Uji } & \multicolumn{1}{c|}{ Kebutuhan Fungsional } & \multicolumn{1}{c|}{ Pengamatan } \\
\hline Klik Play pada & Hardware motion sensor kinect & Sensor kinect terdeteksi, \\
Halaman info game & terdeteksi, muncul tampilan live & muncul tampilan live view \\
terapi Fun Bubble Pop & view user (penderita autis) & berhasil mucul \\
\hline $\begin{array}{l}\text { Ketika game terapi } \\
\text { Fun Bubble Pop }\end{array}$ & Animasi gelembung muncul dan & Gelembung muncul dan \\
Running & melayang-layang secara random. & melayang-layang secara random \\
\hline
\end{tabular}


Citec Journal, Vol. 1, No. 3, Mei 2014 - Juli 2014

Tabel 2. Lanjutan

\begin{tabular}{|l|l|l|}
\hline \multicolumn{1}{|c|}{ Kasus Uji } & \multicolumn{1}{|c|}{ Kebutuhan Fungsional } & \multicolumn{1}{c|}{ Pengamatan } \\
\hline $\begin{array}{l}\text { Ketika user } \\
\text { melakukan gerakan }\end{array}$ & $\begin{array}{l}\text { Motion sensor kinect dapat berjalan } \\
\text { dengan lancar tanpa mengalami } \\
\text { delay lebih dari 3 detik. }\end{array}$ & $\begin{array}{l}\text { Untuk beberapa keadaan terjadi } \\
\text { delay, namun tidak lebih dari 3 } \\
\text { detik. }\end{array}$ \\
\hline $\begin{array}{l}\text { Ketika ujung tangan } \\
\text { menyentuh gelembung }\end{array}$ & $\begin{array}{l}\text { Gelembung berhasil pecah ketika } \\
\text { bersentuhan dengan telapak tangan. }\end{array}$ & $\begin{array}{l}\text { Ketika ujung tangan menyentuh } \\
\text { gelembung maka gelembung } \\
\text { tersebut pecah }\end{array}$ \\
\hline $\begin{array}{l}\text { Ketika aktivitas terapi } \\
\text { sudah selesai }\end{array}$ & $\begin{array}{l}\text { Data hasil terapi sudah terkirim } \\
\text { pada server ahada. }\end{array}$ & Data sudah ada di server. \\
\hline
\end{tabular}

\subsubsection{Pengujian Game Terapi Sensorik - Sound of The World}

Tabel 3. Pengujian Game Terapi Sensorik - Sound of the World

\begin{tabular}{|l|l|l|}
\hline \multicolumn{1}{|c|}{ Kasus Uji } & \multicolumn{1}{|c|}{ Kebutuhan Fungsional } & \multicolumn{1}{c|}{ Pengamatan } \\
\hline $\begin{array}{l}\text { Ketika game terapi } \\
\text { Sound of The World } \\
\text { running }\end{array}$ & $\begin{array}{l}\text { Suara yang harus di identifikasi } \\
\text { berhasil keluar dengan jelas. }\end{array}$ & Suara keluar dengan jelas. \\
\hline $\begin{array}{l}\text { Ketika user memilih } \\
\text { jawaban }\end{array}$ & $\begin{array}{l}\text { Jawaban ada pada salah satu } \\
\text { pilihan jawaban. Dan gambar } \\
\text { ilustrasi harus relevan dengan } \\
\text { teks yang dimunculkan }\end{array}$ & $\begin{array}{l}\text { Gambar yang dimunculkan sudah } \\
\text { sesuai, jawaban yang benar juga } \\
\text { sudah ada pada salah satu pilihan } \\
\text { jawaban }\end{array}$ \\
\hline $\begin{array}{l}\text { Ketika user mampu } \\
\text { mengidentifikasi suara } \\
\text { dengan benar }\end{array}$ & $\begin{array}{l}\text { Aplikasi akan merespon dengan } \\
\text { mengeluarkan suara yang } \\
\text { menyatakan jawaban tersebut } \\
\text { benar. }\end{array}$ & $\begin{array}{l}\text { Aplikasi sudah mengeluarkan } \\
\text { suara tersebut. }\end{array}$ \\
\hline $\begin{array}{l}\text { Ketika user } \\
\text { menginputkan pilihan } \\
\text { dengan menyentuh } \\
\text { jawaban }\end{array}$ & $\begin{array}{l}\text { Apakah aplikasi dapat berjalan } \\
\text { baik dengan media input touch } \\
\text { screen. }\end{array}$ & $\begin{array}{l}\text { Ketika ujung tangan menyentuh } \\
\text { gelembung maka gelembung } \\
\text { tersebut pecah }\end{array}$ \\
\hline $\begin{array}{l}\text { Ketika aktivitas terapi } \\
\text { sudah selesai }\end{array}$ & $\begin{array}{l}\text { Data hasil terapi sudah terkirim } \\
\text { pada server ahada. }\end{array}$ & Data sudah ada di server. \\
\hline
\end{tabular}

\subsubsection{Pengujian Game Terapi Sosial - Activity Sort}

Tabel 4. Pengujian Game Terapi Sosial - Activity Sort

\begin{tabular}{|l|l|l|}
\hline \multicolumn{1}{|c|}{ Kasus Uji } & \multicolumn{1}{|c|}{ Kebutuhan Fungsional } & \multicolumn{1}{c|}{ Pengamatan } \\
\hline $\begin{array}{l}\text { Ketika game terapi } \\
\text { Activity Sort running }\end{array}$ & $\begin{array}{l}\text { Menampilkan screenshot } \\
\text { aktifitas-aktifitas sosial }\end{array}$ & $\begin{array}{l}\text { Screenshot aktifitas-aktifitas } \\
\text { social sudah di tampilkan. }\end{array}$ \\
\hline $\begin{array}{l}\text { Ketika user memilih } \\
\text { jawaban }\end{array}$ & $\begin{array}{l}\text { User dapat melakukan drag and } \\
\text { drop pilihan jawaban dengan } \\
\text { mouse maupun touch }\end{array}$ & $\begin{array}{l}\text { Drag and Drop dengan mouse } \\
\text { lancar, dengan touch juga lancar. }\end{array}$ \\
\hline $\begin{array}{l}\text { Ketika user menjawab } \\
\text { dengan benar }\end{array}$ & $\begin{array}{l}\text { Aplikasi akan menampilkan } \\
\text { video aktifitas secara utuh. }\end{array}$ & Video sudah dapat ditampilkan \\
\hline $\begin{array}{l}\text { Ketika aktivitas terapi } \\
\text { sudah selesai }\end{array}$ & $\begin{array}{l}\text { Data hasil terapi sudah terkirim } \\
\text { pada server ahada. }\end{array}$ & Data sudah ada di server. \\
\hline
\end{tabular}




\subsubsection{Pengujian Game Terapi Kognitif-Pick and Match}

Tabel 5. Pengujian Game Terapi Kognitif - Pick and Match

\begin{tabular}{|l|l|l|}
\hline \multicolumn{1}{|c|}{ Kasus Uji } & \multicolumn{1}{c|}{ Kebutuhan Fungsional } & \multicolumn{1}{c|}{ Pengamatan } \\
\hline $\begin{array}{l}\text { Ketika game terapi Pick } \\
\text { and Match running }\end{array}$ & $\begin{array}{l}\text { Menampilkan gambar-gambar } \\
\text { yang berasosiasi. }\end{array}$ & $\begin{array}{l}\text { Gambar-gambar yang berasosiasi } \\
\text { sudah dapat ditampilkan }\end{array}$ \\
\hline $\begin{array}{l}\text { Ketika user memilih } \\
\text { jawaban }\end{array}$ & $\begin{array}{l}\text { User dapat melakukan drag and } \\
\text { drop pilihan jawaban dengan } \\
\text { mouse maupun touch }\end{array}$ & $\begin{array}{l}\text { Drag and Drop dengan mouse } \\
\text { lancar, dengan touch juga lancar. }\end{array}$ \\
\hline $\begin{array}{l}\text { Ketika aktivitas terapi } \\
\text { sudah selesai }\end{array}$ & $\begin{array}{l}\text { Data hasil terapi sudah terkirim } \\
\text { pada server ahada. }\end{array}$ & Data sudah ada di server. \\
\hline
\end{tabular}

\section{KESIMPULAN}

1. Penerapan konsep game pada sistem terapi autis dengan metode ABA dimulai dengan mengidentifikasi persamaan antara konsep game dan konsep dari metode terapi ABA, setelah itu dilanjutkan dengan merumuskan kebutuhan fungsional terapi autis yang biasa dilakukan disekolah, selanjutnya dari kebutuhan fungsional terapi autis yang telah didapatkan tersebut, dirumuskan lagi menjadi kebutuhan fungsional game terapi yang akan dirancang, diteruskan dengan perancangan game design document, selanjutnya masuk ke tahapan prototyping. Kemudian yang tahapan terakhir yaitu melakukan pengujian mengenai prototype game terapi yang dirancang terhadap kebutuhan game terapi yang telah dirumuskan sebelumnya. Dari pengujian tersebut, diperoleh hasil bahwa semua kebutuhan fungsional game terapi berhasil terpenuhi.

2. Sistem Terapi Autis Ahada terdiri dari dua bagian yaitu Ahada Apps dan Ahada Web Management. Ahada Apps merupakan inti dari sistem ahada, pada bagian ini berisi aplikasiaplikasi terapi autis dengan fungsi dan manfaat yang berbeda-beda. Aplikasi terapi yang berada pada bagian ini dapat dibangun oleh developer pihak ketiga. Sedangkan untuk Ahada Web Management berfungsi untuk menyajikan data autis yang dihasilkan oleh Ahada Apps, sehingga dapat digunakan bagi pihak-pihak yang berada pada level strategis sebagai alat bantu pengambilan keputusan kebijakan publik.

3. Konsep NUI diimplementasikan dengan memanfaatkan teknologi touch screen dan teknologi motion sensor. Penerapan teknologi touch screen digunakan untuk terapi motorik halus, seperti menyentuh dan menge-drag, sedangkan Microsoft Kinect digunakan sebagai motion sensor untuk deteksi gerakan tubuh penderita autis. Dengan NUI Library yang ada pada SDK Microsoft Kinect, gerakan motorik dari penderita autis diolah menjadi sumber inputan dan digunakan untuk memenuhi fungsional kebutuhan game terapi motorik. Namun, sampai saat penelitian ini dilakukan Microsoft belum merelease SDK Kinect untuk windows runtime, sehingga penulis harus menggunakan teknologi apps service yang mampu menjembatani windows x86/64 dengan windows runtime. Hasilnya seperti yang diharapkan, Microsoft kinect dapat digunakan untuk memenuhi kebutuhan game terapi motorik.

\section{SARAN}

1. Pada penelitian ini penulis hanya melakukan pengujian terhadap kebutuhan game terapi, penulis tidak melakukan pengujian terhadap user. Hal ini memberikan peluang untuk penelitian selanjutnya untuk mengukur tingkat keberhasilan game terapi ini terhadap kebutuhan user.

2. Pada penelitian ini aplikasi terapi yang penulis rancang belum dapat menangani aspek penguat negatif yang ada pada metode ABA. Pemberian hukuman bila anak autis 
melakukan kesalahan belum diakomodir pada penelitian ini sehingga diharapkan pada penelitian berikutnya dapat dibahas lebih mendalam mengenai hukuman yang akan diberikan ketika penderita melakukan kesalahan.

3. Pendekatan Game Design Document pada penelitian ini hanya mengadopsi lima dari tujuh jenis Game Design Document menurut Adams Ernest. Sehingga pada penelitian selanjutnya dapat ditambahkan Treatment dan Character Design Document agar dapat menghasilkan rancangan game yang lebih lengkap dan kompleks.

4. Sistem Ahada masih membutuhkan banyak game terapi autis yang mampu berjalan dan terintegrasi pada sistem tersebut. Sehingga perancangan aplikasi-aplikasi terapi autis dengan desain yang lain masih sangat memungkinkan untuk diekplore lagi pada penelitianpenelitian selanjutnya.

\section{DAFTAR PUSTAKA}

[1] Walker, C. E., Roberts, M. C., 1992, Handbook of Clinical Child Psychology, Second Edition, Wiley and Sons, New York.

[2] Ryan, C. S., 2011, Applied Behavior Analysis: Teaching Procedures and Staff Training for Children with Autism, Autism Spectrum Disorders - From Genes to Environment, InTech, Shanghai.

[3] Handojo, Y., 2009, Autisme pada Anak. Menyiapkan Anak Autis untuk Mandiri dan Masuk Sekolah Reguler dengan Metode ABA Basic, Buana Ilmu Populer, Jakarta.

[4] Noor, H. A., Shahbodin, F., Pee, N. C., 2012, Serious Game for Autism Children: Review of Literature, International Conference on Computer Games, Multimedia, and Allied Technology, Venice, Italy.

[5] Casas, X., Herrera, G., Coma, I., Fernández, M., 2012, A Kinect-Based Augmented Reality System for Individuals with Autism Spectrum Disorders, SciTePress, Rome, Italy

[6] Adams, E., 2010, Fundamentals Of Game Design, Second Edition, New Riders, Barkeley

[7] Stefanus, S., 2005, Reverse Engineering - Teori dan Aplikasi, Badan Penerbit Universitas Diponegoro, Semarang. 